\title{
Pensiones de Jubilación a la luz del Acto Legislativo 01 de 2005
}

\section{Retirement Pensions in the light of Legislative Act 01 of 2005}

https://doi.org/10.15332/iust.v0i15.2092

\author{
Luis Eduardo Castellanos Ávila \\ Abogado por la Universidad Libre de Colombia, conciliador en Derecho; especialista en Derecho Constitucional \\ por la Universidad Externado de Colombia, en Derecho Procesal, Derecho Público por la Universidad Santo Tomás \\ Bucaramanga; abogado asesor; consultor litigante, docente de la Universidad Santo Tomás Bucaramanga. \\ Correo electrónico: lecar60@hotmail.com
}

\begin{abstract}
Resumen
El proyecto de investigación presenta una aplicación de una metodología analítica que estudia constitucionalmente el tema central, que tiene como objeto el procurar demostrar cómo el referido Acto Legislativo No. 01 del 2005 modificatorio del artículo 48 de la Constitución Política, además de contrariar disposiciones que consagra la misma Carta Política, en materia del derecho de asociación sindical y negociación colectiva por la restricción que se estableció al ejercicio del derecho a la negociación colectiva, artículo 55 de la C.P., derecho este cuyo arraigo en esencia tiene origen en el derecho fundamental de la asociación sindical, consagrado en el artículo 39 de la Constitución Política, desconociendo lo señalado en los Convenios Internacionales del Trabajo, particularmente el Convenio 87 y 98 (OIT), disposiciones calificadas por la doctrina constitucional como parte integral del denominado Bloque de Constitucionalidad, en virtud del inciso $2^{\circ}$ del artículo 93 de la Constitución Política, característica reforzada por lo determinado en el inciso $4^{\circ}$ del artículo 53 de la Constitución Política. De la misma manera, la enmienda constitucional por la cual se reformó el artículo 48 de la Constitución Política deja ver ostensiblemente cómo se desconoce el derecho a la propiedad privada y a la libertad de empresa al prohibir la negociación colectiva entre particulares, chocando de contera con lo establecido en el artículo 58 de la Constitución Política y lo dispuesto en el artículo 333 constitucional, que garantiza el derecho a la propiedad y el reconocimiento a los derechos adquiridos conforme a la ley, al igual que el derecho a la libertad de empresa bajo una función social determinada.

El análisis del trabajo determinó que la exclusión a la restricción de la negociación colectiva que estableció el Acto Legislativo No. 01 de 2005 en materia pensional configura una antinomia constitucional, que lesiona en forma grave el mecanismo de concertación por medio de la negociación colectiva, que tienen los trabajadores para acordar y mejorar las condiciones mínimas del trabajo previstas en la normativa legal.
\end{abstract}

Palabras clave: Acto Legislativo 01 de 2005, derecho de asociación sindical, negociación colectiva, bloque constitucionalidad, convenios OIT, pensión de jubilación, principio de progresividad, convención colectiva, libertad de empresa y propiedad privada.

\begin{abstract}
The present research project presents an application of an analytical methodology that studies constitutionally the central theme, whose aim is to try to demonstrate how the aforementioned Legislative Act No. 01 of 2005 modifies article 48 of the Political Constitution, in addition to opposing provisions that Enshrines the same Political Charter in relation to the right of trade union association and collective bargaining for the restriction that was established when exercising the right to collective bargaining, article 55 of the Constitution Which is essentially rooted in the fundamental right of trade union association, enshrined in Article 39 of the Constitution, ignoring the provisions of the International Labor Conventions, particularly Convention 87 and 98 (ILO). Constitutional doctrine as an integral part of the so-called Constitutionality Block, pursuant to paragraph 2 of article 93 of the Political Constitution, a feature reinforced by what is determined in paragraph 4 of article 53 Political Constitution.
\end{abstract}


In the same way, the constitutional amendment by which Article 48 of the Political Constitution was reformed, clearly shows how the right to private property and freedom of enterprise is not known by prohibiting collective bargaining between individuals, colliding with the established In article 58 of the Political Constitution and the provisions of article 333 of the Constitution, which guarantees the right to property and recognition of rights acquired under the law, as well as the right to freedom of enterprise under a social function Determined.

In the analysis of the work, it was determined that the exclusion to the restriction of collective bargaining established by Legislative Act No. 01 of 2005 in pension matters constitutes a constitutional antinomy, which seriously damages the mechanism of concertation through collective bargaining, That workers have to agree and improve the minimum conditions of work foreseen in the legal regulations.

Keywords: Legislative Act 01 of 2005, right of association, collective negotiation, constitutional block, OIT conventions, retirement pension, progressive principle, collective bargaining agreement; freedom of enterprise and private property.

\section{Résumé}

Ce projet de recherche présente une application d'une méthodologie d'analyse que l'étude de la Constitution sur le thème, qui vise à tenter de démontrer comment la loi susmentionnée loi $\mathrm{n}^{\circ} 01$ de 2005 modifiant l'article 48 de la Constitution, en plus d'antagoniser dispositions Charte enchâsser la même politique, en ce qui concerne le droit d'association et de négociation collective par la restriction a été mis en place pour exercer le droit à la négociation collective, l'article 55 du CP Ce droit dont les racines, en substance, est enracinée dans le droit fondamental d'association, inscrit à l'article 39 de la Constitution, sans tenir compte ce qui est indiqué dans les conventions internationales du travail, notamment les conventions 87 et 98 dispositions (OIT) classés par la doctrine constitutionnelle en tant que partie intégrante de la soi-disant bloc constitutionnel conformément au paragraphe 2 de l'article 93 de la Constitution, renforcée déterminée au paragraphe 4 de l'article 53 caractéristique Constitution.

De la même manière, l'amendement constitutionnel par lequel l'article 48 de la Constitution politique a été réformé révèle clairement comment le droit à la propriété privée et la liberté d'entreprise sont ignorés lorsqu'il s'agit d'interdire la négociation collective entre des individus en conflit avec l'ordre établi à l'article 58 de la Constitution politique et aux dispositions de l'article 333 de la Constitution, qui garantit le droit de propriété et la reconnaissance des droits acquis conformément à la loi, ainsi que le droit à la liberté d'entreprise sous une fonction sociale déterminé. Dans l'analyse des travaux, il a été déterminé que l'exclusion de la limitation de la négociation collective établie par la loi législative no 01 de 2005 sur les questions de retraite constitue une antinomie constitutionnelle qui porte gravement atteinte au mécanisme de concertation par la négociation collective, que les travailleurs doivent accepter et améliorer les conditions de travail minimales prévues par la législation.

Mots-clés : Acte législatif 01 de 2005; Droit des associations syndicales; Négociation collective; Bloc de constitutionnalité; Conventions de l'OIT; Pension de retraite, principe de progressivité, convention collective; Liberté des affaires et de la propriété privée. 


\section{Pensiones de Jubilación a la luz del Acto Legislativo 01 de 2005}

Luis Eduardo Castellanos Ávila

\section{INTRODUCCIÓN}

En el curso del proyecto de investigación denominado "Pensiones de jubilación a la luz del Acto Legislativo No. 01 de 2005” se efectuó un análisis del contenido literal del Acto Legislativo en mención, que reformó el artículo 48 de la Carta Política, confrontándolo con los principios fundantes del Estado social de derecho que prohijó la Constitución Política de 1991, partiendo del derecho fundamental definido en el artículo 39 "Derecho de Asociación Sindical y el Derecho de Negociación Colectiva" inmerso en el artículo 55 de la norma superior, así mismo, frente a los Convenios de la Organización Internacional del Trabajo calificados como fundantes, como son el Convenio 87 "Derecho de Asociación Sindical" y el Convenio 98 "Relativo a la Negociación Colectiva", que conforman en Stricto sensu el denominado Bloque de Constitucionalidad acorde a los artículos 93, 94 y 53 constitucionales en su inciso $4^{\circ}$, que incorpora los mismos en nuestro ordenamiento jurídico interno.

\section{APROXIMACIÓN AL MARCO TEÓRICO}

Partiendo de la base de que es un estudio socio-jurídico explicativo, que se realiza desde la vigencia del Acto Legislativo 01 de 2005 y su implementación, teniendo en cuenta los efectos causados a los regímenes pensionales de jubilación convencionales existentes, se hizo un análisis frente a la consagración de estos derechos que otorgan las normas internacionales de la OIT (Convenio 87 y 98), el Bloque de Constitucionalidad, los principios constitucionales mínimos protectores del trabajo que estableció el Constituyente en la Carta Política de 1991, y en idéntico sentido se valoró el alcance del polimencionado acto legislativo, respecto a la regulación constitucional establecida en el artículo 374 y 377, en cuanto a las competencias del Congreso de la República como constituyente derivado y la afectación que en igual forma produjo esta enmienda constitucional respecto al derecho a la propiedad privada y demás derechos adquiridos (art. 58 de la C.P.), y la garantía constitucional de la libertad de empresa art. 333 de la misma norma superior, examen crítico 
desde la perspectiva constitucional, que caracterizó a Colombia a partir de 1991 como un Estado social democrático de derecho, cuyo pilar esencial reposa sobre el reconocimiento y respecto a la dignidad humana y el valor fundante que se otorgó al derecho al trabajo bajo condiciones dignas y justas y el realce que se consagra al artículo 39 de la C.P., como derecho fundamental para el ejercicio de la asociación sindical y sus libertades y garantías para ejercerlo, del cual hace parte el derecho de negociación colectiva en el artículo 55 de la C.P., sin restricción alguna.

\section{METODOLOGÍA}

Se utilizó una metodología analítica socio-jurídica, bajo la cual se efectuó un estudio constitucional en relación con los principios, objetivos y fines esenciales del Estado social de derecho, en materia de asociación sindical y negociación colectiva, así como el origen y desarrollo de la Organización Internacional del Trabajo y particularmente los Convenios 87 y 98 relativos al derecho de asociación sindical y negociación colectiva, desprendiéndose de ellos los aspectos jurídicos frente a los cuales se encauzó el Acto Legislativo No. 01 de 2005.

En atención a lo anterior, el tipo de investigación adoptado fue básico teórico de tipo jurídico descriptivo, ya que se llevó a cabo el estudio del articulado constitucional y las normas de los Tratados Internacionales del Trabajo - OIT, para lograr constituir los objetivos del trabajo de investigación.

En la investigación, las fuentes primarias de estudio fueron: los convenios de la OIT, Declaración Universal de los Derechos Humanos, la Constitución Política, las normas y la doctrina. Las fuentes secundarias exploradas fueron, las tesis, los artículos de revista, los libros, la jurisprudencia, entre otras.

Paralelo a esto se efectuó la técnica de la observación teórica, normativa y doctrinal para dar cumplimiento con el objetivo específico central. Como instrumentos se hizo uso de las fichas de análisis jurisprudencial, normativo y doctrinal.

Dentro de los principios relevantes se consideró el Derecho de Asociación Sindical y Negociación Colectiva, el contraste entre principios y Convenios de la OIT y el Acto Legislativo 01 de 2005, los efectos y alcances en el derecho de negociación colectiva, frente al Acto Legislativo 01 de 2005.

\section{DE LA ORGANIZACIÓN INTERNACIONAL DEL TRABAJO - OIT}

\section{Su origen}

La Organización Internacional del Trabajo es un organismo especializado, perteneciente a las Naciones Unidas, y nace en 1919 como uno de los resultados más importantes del Tratado de Versalles al término de la Primera Guerra Mundial, 
siendo producto de la necesidad de abolir varias prácticas que violentaban no solo derechos laborales del hombre, sino derechos humanos fundamentales.

La OIT tiene como principal característica una integración tripartita, y se compone de la Conferencia Internacional del Trabajo, la cual se reúne anualmente en Ginebra integrada por dos representates del gobierno de cada Estado, un representante de patrones, y otro de los trabajadores; como segundo elemento de composición tiene un Consejo de Administración como órgano ejecutivo y, por último, la Oficina Internacional del Trabajo que funge como Secretaría permanente, su preámbulo de la constitución recogió como aspecto esencial que

La paz universal y permanente solo puede basarse en la justicia social, (...) considerando que si cualquier nación no adoptare un régimen de trabajo realmente humano, esta omisión constituiría un obstáculo a los esfuerzos de otras naciones que deseen mejorar la suerte de los trabajadores en sus propios países. (...).

En virtud a esto, la importancia de respetar los convenios promulgados por parte de la OIT por todos los países miembros en que los mismos surgen de la concertación entre trabajadores, Estado y empresarios que conforman la conferencia general de este importante organismo.

La Conferencia Internacional del Trabajo, reunida en 1944 adoptó la Declaración de Filadelfia en la que se definen nuevamente los fines y objetivos de la Organización, basándose en los principios siguientes:

El trabajo no es una mercancía; la libertad de expresión y de asociación es esencial para el progreso constante; la pobreza en cualquier lugar constituye un peligro para la prosperidad de todos; todos los seres humanos sin distinción de raza, credo o sexo tienen derecho a perseguir su bienestar material y su desarrollo espiritual en condiciones de libertad, dignidad, seguridad económica e igualdad de oportunidades.

La OIT tiene como actividad principal emitir normas internacionales de trabajo, las cuales determinan las condiciones mínimas en derechos laborales fundamentales, como libertad sindical, derecho de sindicación, derecho de negociación colectiva, abolición del trabajo forzoso, igualdad de oportunidades y de trato, así como otras normas por las que se regulan condiciones que abarcan todas las cuestiones relacionadas con el trabajo, y dichas normas serán divididas en: convenios, que son Tratados Internacionales sujetos a ratificación por los Estados miembros, y recomendaciones, que sin ser instrumentos vinculantes habitualmente versan sobre los mismos temas que los convenios, teniendo como objetivo orientar la política y la acción de cada nación.

Como vemos, la Organización Internacional del Trabajo es producto de una noble conciencia internacional acerca de que los trabajadores a nivel mundial tienen 
características y necesidades similares de clase, sin importar las diferencias culturales que se puedan presentar, a pesar de la integración colegiada de la organización, se percibe una clara inclinación al proteccionismo de la clase trabajadora, proteccionismo que es necesario, ya que los trabajadores son la clase más desprotegida, frente a la relación de capital trabajo.

\section{De los Convenios 87, 98 de la OIT}

Los convenios 87 y 98 de la OIT hacen parte del Bloque de Constitucionalidad, al ser los dos primeros convenios parte de los ocho convenios esenciales de la OIT, generadores de obligaciones erga omnes, para garantizar las adecuadas relaciones entre trabajadores y empleadores, entre estos y el Estado y la derivación esencial que estas relaciones conllevan hacia un respeto para la adquisición de nuevas prerrogativas, entre ellas mejorar las condiciones de jubilación, vejez, invalidez, subsidios por estos componentes y demás aspectos que pueda comprender el campo de pensiones y de lo negociable dentro de las posibilidades jurídicas y económicas.

El Convenio 87 de la OIT, en su artículo 2:

...Los trabajadores y los empleadores, sin ninguna distinción y $\sin$ autorización previa, tienen el derecho de constituir las organizaciones que estimen convenientes, tal como el de afiliarse a estas organizaciones, con la sola condición de observar los estatutos de las mismas.

En todo caso, la negociación colectiva va regida por los principios de: a) negociación libre y voluntaria; b) libertad para decidir el nivel de negociación $\mathrm{y} ; \mathrm{c})$ buena fe., principios que hacen parte del núcleo intangible del aludido derecho...

En ese orden de ideas, el art. 4 del Convenio 98 de la OIT, establece:

Deberán adoptarse medidas adecuadas a las condiciones nacionales, cuando ello sea necesario, para estimular y fomentar entre los empleadores y las organizaciones de empleadores, por una parte, y las organizaciones de trabajadores, por otra, el pleno desarrollo y uso de procedimientos de negociación voluntaria, con objeto de reglamentar, por medio de contratos colectivos, las condiciones de empleo...

\section{Los convenios de la OIT calificados como esenciales}

La Declaración de Copenhague de 1998 concluyó que existían 8 convenios esenciales, dentro de los cuales se encuentran los convenios 87 sobre libertad sindical y 98 sobre libertad sindical y negociación colectiva.

En dicha Declaración se dijo:

Considerando que la creación de la OIT procedía de la convicción de que la justicia social es esencial para garantizar una paz universal y permanente; 
Considerando que el crecimiento económico es esencial, pero no suficiente, para asegurar la equidad, el progreso social y la erradicación de la pobreza, lo que confirma la necesidad de que la OIT promueva políticas sociales sólidas, la justicia e instituciones democráticas; Considerando que, por lo tanto, la OIT debe hoy más que nunca movilizar el conjunto de sus medios de acción normativa, de cooperación técnica y de investigación en todos los ámbitos de su competencia, y en particular en los del empleo, la formación profesional y las condiciones de trabajo, a fin de que en el marco de una estrategia global de desarrollo económico y social, las políticas económicas y sociales se refuercen mutuamente con miras a la creación de un desarrollo sostenible de base amplia.(...).

\section{La Conferencia Internacional del Trabajo}

1. Recuerda:

a) Que al incorporarse libremente a la OIT, todos los Miembros han aceptado los principios y derechos enunciados en su Constitución y en la Declaración de Filadelfia, y se han comprometido a esforzarse por lograr los objetivos generales de la Organización en toda la medida de sus posibilidades y atendiendo a sus condiciones específicas;

b) Que esos principios y derechos han sido expresados y desarrollados en forma de derechos y obligaciones específicos en convenios que han sido reconocidos como fundamentales dentro y fuera de la Organización.

2. Declara que todos los Miembros, aun cuando no hayan ratificado los convenios aludidos, tienen un compromiso que se deriva de su mera pertenencia a la Organización de respetar, promover y hacer realidad, de buena fe y de conformidad con la Constitución, los principios relativos a los derechos fundamentales que son objeto de esos convenios, es decir:

a) La libertad de asociación y la libertad sindical y el reconocimiento efectivo del derecho de negociación colectiva...

Derechos calificados como fundamentales al interior de la Organización Internacional del Trabajo que como normas de orden público internacional constituyen para los Estados partes una obligación erga omnes, así lo ha expresado el Tribunal Internacional de Justicia en lo que corresponde a esta caracterización:

Las obligaciones erga omnes incorporan valores esenciales para la comunidad internacional, por lo que no es relevante únicamente el tamaño o amplitud del grupo de sujetos internacionales frente al que se asume el compromiso en cuestión, sino el contenido material de dicho compromiso. Este es el quid de la diferenciación entre el concepto exclusivamente etimológico y el concepto manejado por el TIJ en el pronunciamiento analizado. 
Respecto a la declaración de la OIT acerca de que los Convenios 87 y 98 son esenciales, resulta para los Estados una obligación erga omnes, que compromete su responsabilidad, amén de tener una implicación normativa en la medida en que como producen efectos frente a todo el mundo, tal aspecto conlleva su obedecimiento.

En esta línea, la Declaración de la OIT relativa a los principios y derechos fundamentales en el trabajo de junio de 1998, recordaba que estos constituían una obligación "erga omnes, y por tanto son vinculantes para todos los países independientemente de los convenios ratificados. Concretamente estos principios se tradujeron en cuatro categorías en la que los Estados se comprometen a respetar los principios y compromisos vigentes: Libertad de asociación, libertad sindical y reconocimiento efectivo del derecho de negociación colectiva...

\section{Los convenios de la OIT forman parte del bloque de constitucionalidad}

No todos los convenios internacionales del trabajo forman parte del Bloque de Constitucionalidad. En esto, la Jurisprudencia de la Corte Constitucional como guardián supremo de la Carta Política, ha modulado su Jurisprudencia hasta considerar que solamente forman parte del Bloque de Constitucionalidad aquellos convenios que expresamente la misma Corte haya señalado. Es así que como el inciso $4^{\circ}$ del art. 53 de la Constitución se puede señalar sin ninguna duda que todos los convenios internacionales del trabajo ratificados por Colombia fueron integrados a la legislación interna, por expresa disposición constitucional.

Vale la pena resaltar cómo Colombia hasta el año 2002 había ratificado 55 convenios, de los 185 que había aprobado la OIT hasta 2003. Pues bien, los convenios ratificados por Colombia también se refieren a una amplia diversidad de temas, que abarcan desde los derechos humanos fundamentales en el trabajo (como los convenios 87 y 98, relativos a la libertad sindical, al derecho de sindicación y a la negociación colectiva; los números 29 y 105, relativos a la abolición del trabajo forzoso, etc.) hasta las estadísticas del trabajo (convenio 160), pasando por los asuntos de la simplificación de la inspección de los emigrantes (convenio 21), de la inspección del trabajo (convenios 81 y 129) y de la preparación de las memorias sobre la aplicación de convenios por parte del Consejo de Administración de la OIT (Convenio 116).

Según lo anterior, es preciso distinguir entre los convenios de la OIT, puesto que si bien todos los que han sido "debidamente ratificados" por Colombia "hacen parte de la legislación interna” (C.P. art. 53, inciso $4^{\circ}$ ), en otras palabras, son normas jurídicas principales y obligatorias para todos los habitantes del territorio nacional, sin necesidad de que una ley posterior los desarrolle en el derecho interno no todos los convenios forman parte del bloque de constitucionalidad como lo establece la Constitución Política en su artículo 93, en razón a que algunos no reconocen ni regulan derechos humanos, sino aspectos administrativos, estadísticos o de otra índole no constitucional. 
Es claro que algunos convenios deben necesariamente formar parte del bloque de constitucionalidad, puesto que protegen derechos humanos en el ámbito laboral, dándole plena efectividad al principio fundamental de protección al trabajador (art. 1 de la C.P.) y al derecho al trabajo (art. 25 y 53 de la C.P.). Cuando algún convenio prohíba la limitación de un derecho humano durante un estado de excepción o desarrolle tal prohibición, corresponde a la Corte señalar específicamente su pertenencia al bloque de constitucionalidad en sentido estricto (C.P. art. 93, inciso $1^{\circ}$ ).

Frente al análisis del caso se puede afirmar que los convenios 87, 98 de la OIT forman parte del bloque de constitucionalidad, por mandato de los dos incisos del art. 93, el segundo de los cuales dice: "Los derechos y deberes consagrados en esta Carta, se interpretarán de conformidad con los Tratados Internacionales sobre derechos humanos ratificados por Colombia", lo cual significa que es en virtud del inciso $2^{\circ}$ del art. 93 que los convenios 87 y 98 de la OIT hacen parte del bloque de constitucionalidad.

\section{El bloque de constitucionalidad en sentido estricto y en sentido lato}

La Corte Constitucional ha distinguido entre bloque de constitucionalidad en sentido estricto y en sentido lato.

Los convenios que integran al primero, prevalecen en el orden interno, en cuanto prohíben la limitación de un derecho humano bajo los estados de excepción y en consecuencia hacen parte del parámetro de control constitucional de las normas legales que regulan la materia.

A su vez, los convenios que forman parte del bloque de constitucionalidad en sentido lato sirven como referente para interpretar los derechos de los trabajadores y darle plena efectividad al principio fundamental de la protección del trabajador (C.P. art. 1) y al derecho al trabajo (C.P. arts. 25 y 53).

Es decir cuando algún convenio prohíba la limitación de un derecho humano durante un estado de excepción o desarrolle tal prohibición, corresponde a la Corte señalar específicamente su pertenencia al bloque de constitucionalidad en sentido estricto (C.P. en su art. 93, inciso $1^{\circ}$ ) criterio sostenido por la Doctrina Constitucional.

Frente al análisis del caso se puede afirmar que los convenios 87, 98 de la OIT, forman parte del bloque de constitucionalidad en estricto sensu, por mandato de los dos incisos del art. 93, el segundo de los cuales dice: "Los derechos y deberes consagrados en esta Carta, se interpretarán de conformidad con los Tratados Internacionales sobre derechos humanos ratificados por Colombia".

\section{Otros convenios internacionales para la protección de los derechos humanos en materia del trabajo}

En el plano internacional, la Declaración Universal de los Derechos Humanos expedida por la Asamblea General de la Organización de las Naciones Unidas en 1948 consagra el derecho al trabajo (art. 23); el Pacto Internacional de Derechos 
Económicos, Sociales y Culturales (1966), aprobado por la Ley 74 de 1968, consagra el derecho al trabajo (art. $6^{\circ}$ ), el derecho al goce de condiciones de trabajo equitativas y satisfactorias (art. $7^{\circ}$ ) y la libertad de asociación sindical (art. $8^{\circ}$ ); y el Protocolo Adicional a la Convención Americana sobre Derechos Humanos en Materia de Derechos Económicos, Sociales y Culturales "Protocolo de San Salvador" (1988), aprobado por la Ley 319 de 1996, prevé el derecho al trabajo (art. $6^{\circ}$ ), el derecho al goce de condiciones justas, equitativas y satisfactorias de trabajo (art. $7^{\circ}$ ) y los derechos sindicales (art. $8^{\circ}$ ).

Normas que se suman a las adoptadas por la Organización Internacional del Trabajo - OIT, de la cual forma parte el Estado colombiano.

\section{La integración de los conceptos anteriores}

Analizados los conceptos anteriores, tenemos que desde el bloque de constitucionalidad los convenios 87, 98 hacen parte de nuestra Constitución; los dos primeros son esenciales, con efecto erga omnes, esto es, exigibles frente a todo el mundo independientemente de si el país los ratificó o no, amén de ser el piso mínimo o norma mínima que debe regir en materia de libertad sindical y negociación colectiva; en el contenido de los dos (2) tratados está permitida la negociación colectiva en pensiones; tales convenios no pueden ser desconocidos a pesar de la legislación interna; hasta tanto no sean denunciados por el Estado colombiano, ante los órganos de control de la OIT, instancia inicial de interpretación de los convenios, o exista decisión alguna de la Corte Internacional de Justicia frente a los mismos, por lo cual se debe permitir que las partes en la negociación colectiva, puedan mejorar las prestaciones legales sobre pensiones y esquemas de pensiones por mutuo acuerdo; las funciones integradoras, interpretativa y sistemática del bloque de constitucionalidad dan pie a dar prevalencia a la negociación colectiva en pensiones de jubilación.

\section{LA CONTRADICCIÓN CONSTITUCIONAL PROPÓSITO DEL ACTO LEGISLATIVO No. 01 DE 2005}

\section{De las normas en conflicto}

Algunas normas de la Constitución Política que para el caso nos interesa conocer son las siguientes:

El art. 39 Derecho de Asociación Sindical por demás Fundamental.

El art. 55 inciso 1 de la Constitución establece:

Se garantiza el derecho de negociación colectiva para regular las relaciones laborales, con las excepciones que señale la ley.

Por su parte el parágrafo $2^{\circ}$ del art. 48 de la misma Carta, adicionado por el Acto Legislativo No 01 de 2005, es del siguiente tenor: 
A partir de la vigencia del presente acto legislativo no podrán establecerse en pactos, convenciones colectivas de trabajo, laudos o acto jurídico alguno, condiciones pensionales diferentes a las establecidas en las leyes del sistema general de pensiones...

PARÁGRAFO TRANSITORIO $3^{\circ}$. Las reglas de carácter pensional que rigen a la fecha de vigencia de este acto legislativo contenidas en pactos, convenciones colectivas de trabajo, laudos o acuerdos válidamente celebrados, se mantendrán por el término inicialmente estipulado. En los pactos, convenciones o laudos que se suscriban entre la vigencia de este acto legislativo y el 31 de julio de 2010, no podrán estipularse condiciones pensionales más favorables que las que se encuentren actualmente vigentes. En todo caso perderán vigencia el 31 de julio de 2010.

Como se observa, la primeras normas da campo abierto al Derecho Fundamental de Asociación Sindical y al ejercicio consecuencial de la negociación colectiva en todas las áreas, con las limitaciones de ley, que se refieren a ciertos empleados públicos y bajo ciertas condiciones, mas no hay prohibición en cuanto a materias objeto de negociación colectiva. En cambio, los dos parágrafos, presentan una prohibición al derecho de negociación colectiva, en el campo de las pensiones de jubilación.

La situación de contradicción constitucional se agudiza más, si se tiene en cuenta que bajo la noción de Constitución abierta, se acepta el reenvío de normas internacionales del trabajo, a través de la noción de bloque de constitucionalidad. Específicamente, el inciso 4 del art. 53 de la misma Constitución, cuando establece que los convenios internacionales del trabajo debidamente ratificados hacen parte de la legislación interna.

Dentro de los convenios internacionales del trabajo, ratificados por Colombia, se encuentran los convenios 87,98 , que hacen alusión a la libertad sindical y a la negociación colectiva, sin restricción alguna, lo cual conlleva que se encuentre permitida la negociación colectiva en el ámbito pensional e inclusive por encima del mínimo establecido en las leyes.

Los referidos convenios 87,98 , ratificados por Colombia, hacen parte del bloque de constitucionalidad, tal como lo ha expresado en varias oportunidades la Corte Constitucional.

Ahora bien, no todo queda en las disposiciones normativas citadas, pues, el art. 93 de la misma Carta Política, prescribe que los tratados y convenios internacionales ratificados por el Congreso, que reconocen los derechos humanos y que prohíben su limitación en los estados de excepción, prevalecen en el orden interno. Los derechos y deberes consagrados en esta carta, se interpretarán del mismo modo con los tratados internacionales sobre derechos humanos ratificados por Colombia.

Esta última norma comprende dos aspectos fundamentales, como son la prevalencia de los tratados internacionales que reconocen derechos humanos y que 
prohíben su suspensión dentro de los estados de excepción, por un lado; y por el otro, la interpretación de los derechos y deberes conforme a los tratados internacionales, interpretación esta de carácter prevalente.

Aún más, entra en conflicto los referidos parágrafos del Acto Legislativo No. 01 de 2005 con el art. 1 de la Constitución, cuando le da prevalencia al interés general y, con el art. 9 de la C.P., bajo el cual las relaciones exteriores se fundamentan en la soberanía nacional, en el respeto a la autodeterminación de los pueblos y en el reconocimiento de los principios del derecho internacional aceptados por Colombia, dentro de los cuales se encuentra el respeto a los tratados ratificados, sobre todo si los mismos imponen obligaciones erga omnes y provienen de la voluntad tripartita: Estado, empleadores y trabajadores.

\section{LA ANTINOMIA COMO PROTAGONISTA DE LA TENSIÓN ENTRE LA CONSTITUCIÓN POLÍTICA, LOS TRATADOS INTERNACIONALES DE LA OIT Y EL ACTO LEGISLATIVO No. 01 DE 2005}

La expedición del Acto Legislativo No. 01 de 2005 que reformó el artículo 48 de la Constitución Política, bajo la iniciativa del Gobierno Nacional, deja como protagonista una tensión entre disposiciones constitucionales e igualmente frente a los convenios internacionales del trabajo, en materia de asociación sindical y negociación colectiva debidamente ratificados e incorporados en nuestro ordenamiento jurídico, que necesariamente debe calificarse como una antinomia, toda vez, que si bien es cierto el artículo 48 de la C.P. reformado por el acto legislativo mencionado prohibió la negociación colectiva en materia de pensiones de jubilación, a su vez, este derecho permanece intacto bajo el amparo del artículo 53 inciso $4^{\circ}$ "Convenios OIT" y artículo 55 de C.P. "Negociación Colectiva", bajo el criterio definido por el constituyente primario en el año 91, sin restricción alguna para el ejercicio de estos derechos, siendo en consecuencia ostensible la contradicción entre las normas constitucionales señaladas.

\section{Un breve concepto de antinomia}

Se dice que hay una antinomia (Gascón, 1997) cuando en el ordenamiento jurídico existen dos o más normas que regulan de modo diferente e incompatible un mismo supuesto de hecho.

Siguiendo a Alf Ross (1963), la inconsistencia puede ser total-total, en cuyo evento ninguna de las normas puede ser aplicada bajo ninguna circunstancia sin entrar en conflicto con la otra; la inconsistencia total-parcial, se da cuando una de las dos normas no puede ser aplicada bajo ninguna circunstancia sin entrar en conflicto con la otra, mientras que esta tiene un campo adicional de aplicación en el cual no entra en conflicto con la primera y finalmente la inconsistencia es parcial-parcial, cuando 
una de las dos normas tiene un campo de aplicación en el cual entra en conflicto, pero también tiene un campo adicional de aplicación en el cual no se produce conflicto.

De acuerdo con el jurista italiano Ricardo Guastini (2010, pp. 56 y 57), los conflictos normativos pueden ser "in abstracto" e "in concreto". El primero se produce cada vez que dos normas vinculan consecuencias jurídicas incompatibles a dos clases de hechos o, si se quiere dos soluciones incompatibles a dos clases de diferendos que se superponen (total o parcialmente), desde el punto de vista conceptual. Es decir, haciendo abstracción de todo caso de especie, de todo diferendo particular.

El conflicto in concreto se presenta cuando, al momento de la aplicación del derecho en un caso especial, dos normas vinculan dos consecuencias jurídicas incompatibles al mismo caso concreto. Podemos decir que, la antinomia o conflicto que se analizará se da en abstracto por un lado y es total parcial por el otro.

\section{EL NÚCLEO ESENCIAL DE UN DERECHO FUNDAMENTAL}

Independientemente de cualquier teoría sobre el núcleo duro de los derechos fundamentales, sea espacial, temporal, absoluta o relativa, el núcleo esencial de un derecho fundamental, hace relación con aquella parte del contenido del derecho que es absolutamente necesaria para que los intereses jurídicamente protegibles, que dan vida al mismo, resulten real, concreta y efectivamente protegidos. En ese sentido, se desconoce o rebasa el contenido esencial cuando el derecho queda sometido a limitaciones que lo hacen impracticable, lo dificultan más allá de lo razonable o lo despojan de la necesaria protección.

El núcleo esencial es aquel mínimo que siempre debe permanecer en el derecho, antes y después, pues si desaparece, el derecho deja de ser aquello a lo que la Constitución se refiere, aunque solo sea en alguno de sus elementos.

La teoría del núcleo esencial va encaminada a establecer límites al legislador que desarrolla los derechos fundamentales.

Aún más, entran en conflicto los referidos parágrafos del Acto Legislativo con el art. 1 de la Constitución, cuando le da prevalencia al interés general y, con el art. 9, según el cual las relaciones exteriores se fundamentan en la soberanía nacional, en el respecto a la autodeterminación de los pueblos y en el reconocimiento de los principios del derecho internacional aceptados por Colombia, dentro de los que se encuentra el respecto a los tratados ratificados, sobre todo si estos imponen obligaciones erga omnes y provienen de la voluntad tripartita: Estado, empleadores y trabajadores.

En Colombia existe un caso tipo de fenómeno normativo en el que penetran principios de la economía de mercado en los derechos sociales constitucionales y en el que se supedita la existencia y el ejercicio de estos al respeto de los principios económicos y de la viabilidad financiera del sistema. A partir del Acto Legislativo 01 de 2005 se establece la seguridad financiera del sistema de la seguridad social 
como nuevo imperativo categórico cuyo respeto debe ser impuesto al Estado. Esto dentro de un marco general de adopción de las políticas económicas por los sistemas de seguridad social en los países occidentales después de la crisis económica de 1973 y que los obliga a adaptarse a estas.

Con esta reforma constitucional, el sistema financiero colombiano juega un papel demasiado importante en el otorgamiento de los derechos sociales de las personas, esto es, logró ganar el principio económico dentro del derecho social a la seguridad social y a la negociación colectiva. Se pretende de ahora en adelante, que ni jueces ni legislador puedan escindir la seguridad financiera del sistema del derecho a la seguridad como tal. Lo que significara que muchas personas verán cómo su derecho será negado a la luz de un principio económico que puede estar incluso por encima de un derecho fundamental. Si en la Constitución de 1991 se establecieron, principios sociales y principios económicos comparados por aquel que tenía más peso, lo cual ha sido avalado también por la metodología constitucional de la ponderación de principios, con el Acto Legislativo 01 de 2005 no queda duda que el principio económico logró permear directamente un principio social, dejándolo sin defensa alguna, sin interpretación o aplicación propia, sin filosofía autónoma.

\section{DEL DERECHO DE ASOCIACIÓN Y NEGOCIACIÓN COLECTIVA EN LA CONSTITUCIÓN DE 1991}

El derecho de asociación sindical revistió gran importancia para el constituyente primario, cuando plasmó con rango de canon constitucional en el art. 39 de la Carta Política de 1991 el derecho de asociación sindical como derecho fundamental, incorporando las garantías y libertades necesarias para el ejercicio de este derecho, y su consecuencia jurídica, cuyo núcleo esencial es la negociación colectiva (art. 55 de la C.P.), reafirmándose con ello la caracterización de un Estado social democrático de derecho, bajo el cual adquirió especial preponderancia constitucional el derecho al trabajo (art. 25 de la C.P) como valor fundante de respeto y desarrollo de estas garantías constitucionales a partir del preámbulo y el (artículo 1 de la C.P.), en una determinación de estructura fundamental bajo el reconocimiento y respecto de la dignidad humana y un trabajo en condición justa, previendo metas hacia las cuales debe orientarse el rumbo de las instituciones jurídicas laborales para fortalecer el tejido social a través de las garantías de un orden económico, social, justo y equitativo, como un fin estructural del Estado para promover la prosperidad en general de la población trabajadora, sobre la base del diálogo y la concertación entre empleados y trabajadores y sus organizaciones sindicales.

Esto en completa armonía con el Convenio 87 “Asociación Sindical” y el Convenio 98 "Negociación Colectiva" de la OIT incorporado en nuestro ordenamiento por la Ley 26 y 27 de 1976, que permite la protección y desarrollo de estas garantías en el marco del derecho internacional del trabajo. 
Debo resaltar que la Constitución Política establece en el inciso $4^{\circ}$ del art. 53 que los convenios internacionales del trabajo debidamente ratificados hacen parte del ordenamiento interno jurídico, por la inclusión automática que genera la disposición constitucional, y en idéntico sentido la sólida jurisprudencia constitucional ha sostenido en forma pacífica y reiterada que por tratarse dichos convenios de derechos humanos laborales, los mismos integran en estricto sentido el llamado Bloque de Constitucionalidad, a partir del mismo art. 1 de la Constitución Política, los artículos 2, 5, 9, 39, 55, 93 y 94 (Sentencia C-401 del 2005).

De ahí la relevancia que adquiere el desarrollo del derecho de negociación colectiva a partir de la Carta Política en su art. 55, regulada en el art. 467 del Código Sustantivo del Trabajo que define, la convención colectiva de trabajo suscrita bajo la negociación colectiva por voluntad de las partes como un mecanismo jurídico capaz de regular las condiciones laborales entre empleadores y trabajadores representados por la organización sindical, con fuerza vinculante para las partes respecto a lo allí establecido.

Máxime si se toma en cuenta lo acordado por la doctrina constitucional en cuanto que las mismas emergen del ejercicio del derecho constitucional a la negociación colectiva pero igualmente del desarrollo pleno del derecho fundamental acordado en el título II capítulo 1 de la Constitución Política en su art. 39 "Derecho de Asociación Sindical".

\section{PRINCIPIO DE PROGRESIVIDAD Y PROHIBICIÓN DE REGRESIVIDAD EN MATERIA DE DERECHOS SOCIALES}

El Principio de progresividad de los derechos sociales, económicos y culturales (DESC) y la prohibición concomitante de la regresividad de estos derechos se encuentra consagrado en el art. 48 de la C.P. que establece que "El Estado, con la participación de los particulares, ampliará progresivamente la cobertura de la seguridad social...".

Además se debe tener en cuenta que el Principio de progresividad y la prohibición de regresividad de los DESC se encuentra consagrados en las normas de derecho internacional que hacen parte del bloque de constitucionalidad ${ }^{1}$, ya que específicamente se encuentran estipulados en el art. 2 del Pacto Internacional de Derechos Económicos, Sociales y Culturales (PIDESC), que establece que, 'Cada uno de los Estados Partes en el presente Pacto se compromete a adoptar medidas, tanto por separado como mediante la asistencia y la cooperación internacionales,

$1 \quad$ El artículo 93 de la C.P. establece que, "Los derechos y deberes consagrados en esta Carta, se interpretarán de conformidad con los Tratados Internacionales sobre derechos humanos ratificados por Colombia". Con base en esta norma se ha introducido en Colombia la idea de que dichos tratados y convenios internacionales sobre derechos humanos firmados y ratificados por Colombia, hacen parte del bloque de constitucionalidad. 
especialmente económicas y técnicas, hasta el máximo de los recursos de que disponga, para lograr progresivamente, por todos los medios apropiados, inclusive en particular la adopción de medidas legislativas, la plena efectividad de los derechos aquí reconocidos'. Del mismo modo en el artículo 11.1 del PIDESC se establece que, 'Los Estados Partes en el presente Pacto reconocen el derecho de toda persona a un nivel de vida adecuado para sí y su familia, incluso alimentación, vestido y vivienda adecuados, y a una mejora continua de las condiciones de existencia'...2.

En cuanto a la recepción de dicho principio en la jurisprudencia constitucional se debe citar en primer lugar la (Sentencia SU-225 de 1997) ${ }^{3}$ que establece que la progresividad de los derechos sociales hace referencia al reconocimiento de prestaciones mayores y superiores de cada uno de estos derechos e implica que una vez alcanzado un determinado nivel de protección no se puede retroceder frente al nivel de protección al que se ha llegado o conseguido. Igualmente se ha acogido dentro de la jurisprudencia de la Corte la interpretación del Principio de no regresividad que han dado los organismos internacionales en el sentido de que el mandato de progresividad de DESC no excusa al Estado del cumplimiento del deber de que con el máximo de los recursos disponibles se provea por la cobertura universal de los contenidos de estos derechos ${ }^{4}$.

Del mismo modo, la jurisprudencia constitucional estableció que el mandato de progresividad implica que una vez alcanzado un determinado nivel de protección de un derecho social existe prima facie la presunción de inconstitucionalidad de todo retroceso y la necesidad de realizar un juicio de constitucionalidad más severo en el caso de que se presenten legislaciones regresivas de estos derechos. Sobre esta presunción de inconstitucionalidad prima facie del retroceso en materia de derechos sociales se dijo en la Sentencia C-038 de 2004 que:

El mandato de progresividad implica que una vez alcanzado un determinado nivel de protección, la amplia libertad de configuración del legislador en materia de derechos sociales se ve restringida, al menos en un aspecto: todo

$2 \quad$ Ver el libro compilado por Christian Courtis titulado "Ni un paso atrás: la prohibición de regresividad en materia de derechos sociales", Buenos Aires, CELS, 2006.

3 M.P. Eduardo Cifuentes Muñoz. En esta Sentencia también se consagró la "Cláusula de erradicación de las injusticias presentes", en donde se ordena a las autoridades estatales adoptar todas las medidas necesarias para garantizar la vacunación gratuita para prevenir meningitis a niños pertenecientes a sectores históricamente marginados. Como se establece en la Sentencia C-727 de 2009 (M.P. María Victoria Calle), esta jurisprudencia ha sido reiterada en otras sentencias, como por ejemplo la T-177 de 1999 (M.P. Carlos Gaviria Díaz); T-840 de 1999 (M.P. Eduardo Cifuentes Muñoz); T-772 de 2003 (M.P. Manuel José Cepeda).

4 Por ejemplo en la Sentencia C-671 de 2002 en donde se dijo que, "La progresividad hace referencia al reconocimiento de prestaciones mayores y superiores en relación con cada uno de esos derechos sociales prestacionales, pero ese mandato de progresividad no excusa el incumplimiento del deber del Estado de asegurar, tan pronto como sea posible, coberturas universales de los contenidos mínimos de esos derecho...". 
retroceso frente al nivel de protección alcanzado es constitucionalmente problemático puesto que precisamente contradice el mandato de progresividad. Como los Estados pueden enfrentar dificultades, que pueden hacer imposible el mantenimiento de un grado de protección que había sido alcanzado, es obvio que la prohibición de los retrocesos no puede ser absoluta sino que debe ser entendida como una prohibición prima facie. Esto significa que, como esta Corte ya lo había señalado, un retroceso debe presumirse en principio inconstitucional, pero puede ser justificable, y por ello está sometido a un control judicial más severo. Para que pueda ser constitucional, las autoridades tienen que demostrar que existen imperiosas razones que hacen necesario ese paso regresivo en el desarrollo de un derecho social...".

\section{EL PRINCIPIO PRO HOMINE O IN DUBIO PRO LIBERTATE}

Es un criterio hermenéutico que entra en la categoría de los derechos humanos, ya que estos son prerrogativas o potestades que se han otorgado a todos los seres humanos, a fin de que se desarrolle plenamente en sociedad en su desarrollo vital, por virtud del cual debe estarse siempre a favor de la persona e implica que debe acudirse a la norma más amplia, o a la interpretación más extensiva, cuando se trata de reconocer derechos protegidos; e inversamente, a la norma o a la interpretación más restringida cuando se trata de establecer restricciones permanentes al ejercicio de los derechos o a su suspensión extraordinaria.

Sobre el tema la Sentencia C-551 de 2003, de la Corte Constitucional señaló:

...Y como, en virtud del principio pacta sunt servanda, las normas de derecho interno deben ser interpretadas de manera que armonicen con las obligaciones internacionales del Estado Colombiano (C.P. art. 9), tal y como esta Corte lo ha señalado, entonces entre dos interpretaciones posibles de una norma debe preferirse aquella que armonice con los Tratados ratificados por Colombia. Esto es aún más claro en materia de derechos constitucionales, puesto que la Carta expresamente establece que estos deben ser interpretados de conformidad con los Tratados ratificados por Colombia (C.P. art. 93), por lo que entre dos interpretaciones posibles de una disposición constitucional relativa a derechos de la persona, debe preferirse aquella que mejor armonice con los Tratados de derechos humanos, dentro del respeto del principio de favorabilidad o pro homine, según el cual, deben privilegiarse aquellas hermenéuticas que sean más favorables a la vigencia de los derechos de la persona. Y por ello la Corte concluye que, de ser aprobado el numeral $1^{\circ}$, debe entenderse que la segunda frase del mismo hace referencia a que la culpa grave o el dolo del servicio público fue establecida por una sentencia judicial ejecutoriada en un proceso penal, y por ello no existe una contradicción entre el numeral $1^{\circ} \mathrm{y}$ la Convención Interamericana, y menos aún este numeral implica una sustitución de la Constitución. 
Debe anotarse que esta máxima interpretativa, no solamente es una directriz de preferencia de interpretaciones entre las varias posibles de un mismo enunciado jurídico, sino una directriz de preferencia de normas, es decir, el juez debe aplicar la norma más favorable a la persona, con independencia de su nivel jurídico. Tal postulado, no exime al jurista de realizar una interpretación armónica o un balanceo de valores, en aras de compatibilizar y hacer convivir distintos derechos entre sí, o algunos derechos con las necesidades del bien común (Sagues, 2006, p. 212).

De igual manera, debe indicarse que la regla general es la libertad y la excepción es la limitación, lo que conlleva a que el anterior postulado no solo se aplique en caso de duda, interpretación oscura o conflicto, sino en todos los eventos.

Por lo anterior, algunos autores (Ribera, 2007, p. 261). Señalan que uno es el principio in dubio pro libértate y otro el principio favor libertatis.

El primero alude a la presunción establecida en términos generales a favor de las libertades de la persona humana, con el objetivo de integrar al proceso interpretativo la importancia de las libertades, y conlleva que en caso de duda o situaciones oscuras, deba optarse por la interpretación que mejor proteja los derechos fundamentales (Ribera, 2007, p. 261).

El segundo, implica un concepto más amplio y extensivo, propugnando por una interpretación constitucional que tienda a maximizar o expandir los derechos fundamentales en su conjunto.

El principio in dubio pro libertate, es una consecuencia de la fuerza expansiva de los derechos fundamentales, integrado por normas finalistas con vocación de irradiar todo el ordenamiento jurídico y a la vez, establece una continuidad con el principio de efectividad de aquellos, esto es, que el sistema de derechos fundamentales potencia su eficacia en todos los ámbitos de la experiencia social o política.

Lo anterior, implica un dinamismo de este tipo de derechos, y su efecto irradiación que permea todo el ordenamiento jurídico, los lleva a su prevalencia no solo en caso de duda, sino en todos los eventos en que entren en conflicto con otros bienes jurídicos.

\section{EL PRINCIPIO DE LA PROPIEDAD PRIVADA Y LA LIBERTAD DE EMPRESA}

Establece el art. 58 de la C.P., ‘... la garantía al respecto al derecho adquirido conforme a la ley, de igual manera consagra como parte de este derecho la propiedad privada....

Artículo 58 C.P. Se garantiza la propiedad privada y los demás derechos adquiridos con arreglo de las leyes civiles, los cuales no pueden ser desconocidos ni vulnerados por leyes posteriores. Cuando de la aplicación de una ley expedida por motivos de utilidad pública o interés social, resultaren en conflicto los derechos de los particulares con la necesidad 
por ella reconocida, el interés privado deberá ceder al interés público o social. La propiedad es una función social que implica obligaciones. Como tal, le es inherente una función ecológica. El Estado protegerá y promoverá las formas asociativas y solidarias de propiedad. Por motivos de utilidad pública o de interés social definidos por el legislador, podrá haber expropiación mediante sentencia judicial e indemnización previa. Esta se fijará consultando los intereses de la comunidad y del afectado. En los casos que determine el legislador, dicha expropiación podrá adelantarse por vía administrativa, sujeta a posterior acción contenciosa-administrativa, incluso respecto del precio.

Aspectos estos que permiten en idéntico sentido reafirmar que estas garantías constituyen una base esencial, que bajo nuestro ordenamiento civil permite a las personas suscribir acuerdos que incluyan obligaciones y deberes recíprocos en materia contractual, por lo cual es importante resaltar los artículo 1495 y 1602 del Código Civil colombiano, que al establecer lo relativo a los contratos y las convenciones expresan en forma clara y precisa que el desarrollo de los mismos tiene como efecto fundante la autonomía de la voluntad de las partes, siendo entonces evidente que al prohibirse en el parágrafo segundo transitorio del Acto Legislativo No. 01 del 2005 que reformó el art. 48 de la Constitución Política, el celebrar convenio o acuerdos de cualquier índole entre personas para establecer pensiones de jubilación con característica y requisitos diferentes a lo previsto en el régimen de seguridad social que estableció la Ley 100 de 1993, quebranta igualmente tal disposición lo relativo a las garantías civiles al adoptarse una decisión bajo enmienda constitucional propia de un sistema absolutista, que no puede tener cabida en un Estado Social Democrático de Derecho como el que promulgó la Constitución de 1991 a partir de su preámbulo, es decir, limitar el derecho de negociación en materia pensional en las convenciones colectivas de trabajo, sobre la premisa de darle sostenibilidad financiera al sistema pensional contradice en forma notoria los principios constitucionales que garantizan el derecho a la propiedad privada y los derechos adquiridos conforme a ley, pues no puede predicarse y mucho menos sustentarse, que la pensión de jubilación pactada entre una empresa privada y una organización sindical cuyo pago está a cargo de dicha entidad con recursos de capital privado pueda afectar las finanzas públicas y particularmente al sistema de seguridad social en el ámbito pensional desde el aspecto financiero.

Pero de igual manera, el art. 333 de la C.P. estableció claramente la protección a la libertad de empresa.

Artículo 333: La actividad económica y la iniciativa privada son libres, dentro de los límites del bien común. Para su ejercicio, nadie podrá exigir permisos previos ni requisitos, sin autorización de la Ley. La libre competencia económica es un derecho de todos, que supone responsabilidades. La empresa, como base del desarrollo, tiene una función social que implica obligaciones. El Estado fortalecerá las organizaciones 
solidarias y estimulará el desarrollo empresarial. El Estado, por mandato de la Ley, impedirá que se obstruya o se restrinja la libertad económica y evitará o controlará cualquier abuso que personas o empresas hagan de su posición dominante en el mercado nacional. La ley delimitará el alcance de la libertad económica cuando así lo exijan el interés social, el ambiente y el patrimonio cultural de la Nación.

Aspectos donde se establece y la reafirmación del Estado Social de Derecho bajo el respecto no solo de la propiedad privada sino a la libertad del fomento y el estímulo de la formación de empresas en nuestro país, aspecto que tiene gran trascendencia si se toma en cuenta que es la incorporación de los múltiples tratados multilaterales celebrados en materia comercial por parte de Colombia en el contexto del proceso de globalización de la economía y en el modelo de mercado imperante, bajo los cuales a la empresa privada le permite un amplio margen de libertad en procura de que las mismas puedan desenvolverse de manera eficiente, eficaces respecto a su productividad no solo en términos financieros, sino igualmente en términos de rentabilidad social, procurando a través de la responsabilidad social aportar al mejoramiento del bien común. Es claro entonces que el polimencionado Acto Legislativo 01 de 2005 al establecerse esta prohibición al derecho de negociación colectiva en forma genérica en materia de pensiones de jubilación, impide tanto a empresarios como a trabajadores representados a través de sus organizaciones sindicales, ejercer el derecho constitucional a la negociación colectiva art. 55 de la Carta Política y puedan adoptar medidas para regular las relaciones laborales, buscando un costo beneficio en el cual las partes resulten gananciosas. Dando de esta manera a la empresa, bajo el criterio de una libertad, que desde el punto de vista constitucional tenga un desarrollo material en el escenario del mercado en que se desenvuelva, constituyéndose en un bastión importante para impulso y crecimiento económico del país.

El Acto Legislativo 01 de 2005 que reformó el art. 48 de la Constitución Política resulta cuestionable, no solo en lo que corresponde a su contraposición respecto de los convenios internacionales de la OIT, especialmente los arts. 87 y 98 incorporados en nuestro ordenamiento jurídico a través de la Ley 26 y 27 de 1976, disposiciones que también están incorporadas en nuestro ordenamiento constitucional por mandato del art. 53 y determinadas como parte del bloque de constitucionalidad como lo determinó la doctrina constitucional bajo el fundamento previsto en los artículos 93 y 94 constitucionales, si no, también raya de igual manera en lo establecido en el art. 58 y art. 333 constitucional que estableció la libertad de empresa y particularmente el principio consagrado en el derecho civil, como es la voluntad de la autonomía de las partes que regula los aspectos societarios de empresas conformadas bajo dicha condición con capitales particulares, de hecho, al prohibirse la negociación colectiva en materia pensional, bajo el argumento de conservar la sostenibilidad financiera de aquellas pensiones con recursos a cargo del Estado particularmente emanados del Presupuesto General de la Nación, no se aprecia en lo más mínimo que una pensión 
otorgada por una empresa privada cuyo capital en esencia hace parte de la propiedad privada y el patrimonio de particulares pueda impactar en manera alguna el sistema pensional colombiano. Pero así mismo, esta limitación a la libertad de empresa como tal genera una afectación directa a lo previsto en el preámbulo de nuestra Constitución Política, en su art. 1 que determina a Colombia como un Estado social democrático de derecho donde especial valor representa el reconocimiento y protección de la dignidad humana y el valor fundante que se le da al trabajo en condiciones dignas y justas, similarmente la garantía establecida como derecho fundamental previsto en el art. 39 de la C.P., y su consecuencia jurídica como parte de la libertad sindical que es el derecho a la negociación colectiva.

Vemos entonces que efectivamente en tal iniciativa de enmienda constitucional como fue el Acto Legislativo 01 de 2005, se desconoció la garantía prevista en el art. 58 de la C.P., en lo que refiere a la propiedad privada, pues al impedir la posibilidad de negociar en una convención colectiva de trabajo condiciones pensionales diferentes a las establecidas en el sistema de seguridad social, bajo un escenario de concertación entre trabajadores y empleadores en una negociación colectiva procurando un costo beneficio para las partes, constituye una grave limitación a uno de los principios liberales que fundan el Estado social democrático de derecho prodigado por la Constitución de 1991, bajo la condición de la Carta Política con estructura antropocéntrica erigida sobre el principio del reconocimiento a la dignidad humana, al trabajo, y las libertades civiles y económicas conforme a las normas invocadas, produciéndose una grave amenaza al Estado social democrático de derecho e igualmente un grave desconocimiento a los convenios y tratos internacionales que a partir de la Declaración Universal de los Derecho Humanos, la Declaración del Protocolo de San Salvador, disposiciones estas dentro del bloque de constitucionalidad reafirman el respecto al derecho constitucional, a la propiedad privada y a la libertad de empresa, dentro del compromiso de responsabilidad social que permite que el desarrollo de las mismas procure lograr el máximo de desarrollo, no solo desde el punto de vista económico sino desde el punto de vista de la condición del trabajo de manera digna y justa para un desarrollo pleno del trabajador y su entorno familiar, disminuyendo en lo posible la inequidad y la pobreza y procurando un desarrollo armónico entre las empresas como empleadores y sus trabajadores como parte importante de nuestra sociedad.

Por consiguiente se reitera que el polimencionado Acto Legislativo 01 de 2005 , reformatorio del art. 48 de la C.P., transgrede el principio de Estado social de derecho ya que impide asegurar las condiciones mínimas de la dignidad humana que demanda asegurar ciertas condiciones necesarias para un buen vivir, y de manera contraria despoja a los trabajadores de conformar en su núcleo personal y familiar unos presupuestos mínimos de vida acordes con el modelo de Estado que eligieron los colombianos, a través de la Constituyente de 1991 en tanto que el término laborales excluye de cualquier responsabilidad a los accionistas frente a las obligaciones laborales. 
Así mismo, resulta notorio cómo el órgano legislativo a través de la expresión acusada vulnera el principio de efectividad, debido a que no ejecuta a cabalidad el principio de trabajo digno y justo, teniendo como resultado la ineficacia de los derechos laborales en materia colectiva, como son el derecho de asociación sindical y la negociación colectiva, para el mejoramiento de las condiciones mínimas laborales previstas en la normatividad legal.

De igual forma, por mandato expreso del constituyente primario, se prohíbe taxativamente al cuerpo legislativo exceder los límites que la Carta Política le impone, pues de ninguna manera puede mediante una ley desconocer los principios mínimos del derecho al trabajo. Es así, como la expresión acusada se aparta de la prohibición constitucional de que la ley menoscabe la libertad, la dignidad humana o los derechos de los trabajadores, al establecer una prohibición a la negociación colectiva en materia de pensiones de jubilación a las empresas privadas cuando su capital y patrimonio son propiedad de los particulares que concurren en su condición de socios, y los derechos económicos derivados de tales acuerdos no impactan en manera alguna el Presupuesto General de la Nación, teniendo en cuenta que las mismas son obligaciones a cargo de recursos económicos particulares propios de cada empresa privada.

La consideración anterior se refuerza de manera clara si se tiene en cuenta la motivación que expresó el Gobierno de Colombia en la exposición de motivos del Acto Legislativo No. 01 de 2005, ante el Congreso de la República, particularmente lo consignado en el Acta No. 49 de la Sesión Plenaria del Senado de la República celebrada el 13 de junio de 2005, publicada en la Gaceta del Congreso No. 474 del 3 de agosto de 2005, donde se expuso entre otras que el principio que perseguía la enmienda constitucional referida era, de un lado, la unificación de los regímenes pensionales en la Ley 100 de 1993, y la desaparición de los regímenes pensionales especiales y excepcionales que existían bajo pluralidad de disposiciones de tipo normativo e igualmente establecer como un principio la sostenibilidad financiera del sistema pensional a cargo del Estado, para disminuir los pasivos que impactan en los recursos porcentuales obtenidos del Producto Interno Bruto y que se destinan presupuestalmente al pago de las mesadas pensionales a cargo del Estado, pero de igual manera disminuir las pensiones de jubilación onerosas que se causaban a los servidores públicos a través de los regímenes especiales como el del Congreso de la República, las Altas Cortes, estableciendo para ello un límite hasta de 25 Salarios mínimo legal mensual vigente, es decir, toda una estrategia por vía de enmienda constitucional procurando optimizar los recursos por parte del Estado, cuya destinación no es otra que atender los pasivos pensionales a cargo de este.

Es decir, siempre se planteó como necesidad imperante para la expedición del Acto Legislativo la sostenibilidad financiera del sistema pensional, el principio de sostenibilidad o equilibrio financiero del sistema general de pensiones, criterios profundamente analizados y debatidos como consta en la Gaceta Oficial que registró el desarrollo de esta iniciativa legislativa, tanto en la Cámara de Representantes como en el Senado de la República. 
Sin embargo, no deja de llamar poderosamente la atención cómo el referido Acto Legislativo en su parte normativa concluye estableciendo una prohibición general al derecho de negociación colectiva entre particulares, en otras palabras, entre personas tanto naturales como jurídicas de carácter privado cuando las pensiones que se acuerdan en una convención colectiva de trabajo por voluntad de las partes en ningún momento impactan los recursos económicos del Estado, pues las mismas son asumidos por parte del empleador hasta el momento en que el trabajador cumple los requisitos para ingresar al sistema de seguridad social en materia de pensión de vejez y a partir de ese momento se constituye este beneficio en una pensión compartida, conforme lo establece el Acuerdo 049 del año 1990 reglamentado por el Decreto 0758 de 1990.

Es importante el resaltar, como la pensión de jubilación de carácter convencional, concebida bajo el principio de la autonomía de la voluntad de las partes, en un proceso de negociación colectiva entre particulares, encuentra igualmente respaldo en lo previsto en el Artículo 1495 y 1602 del Código Civil colombiano, y pleno soporte financiero para el pago de estas obligaciones económicas, en capital económico de origen privado, desvirtuando en consecuencia el espíritu de lo pretendido a través del Acto Legislativo No. 01 de 2005 y lo finalmente previsto en su contenido literal, especialmente en su parágrafo transitorio segundo y tercero, por lo cual se estableció la prohibición general al derecho de negociación colectiva en materia de pensión de jubilación, que como lo hemos venido expresando surge del ejercicio al derecho fundamental de asociación sindical consagrado en los artículos 39 y 55 de la Carta Política y el convenios 87 y 98 de la OIT.

\section{CONCLUSIONES}

Con base en el resultado del análisis efectuado en el desarrollo del presente trabajo de profundización, se puede concluir la evidente tensión jurídica que surge de una parte entre el Acto Legislativo No. 01 de 2005, que reformó el art. 48 de la Constitución Política, por el cual se fijó una prohibición a la negociación colectiva en materia de pensiones de jubilación, y lo previsto en la Constitución de 1991, a partir de su preámbulo y los fines esenciales que caracterizan el Estado social de derecho que prohijó el constituyente primario, y concretamente frente a los artículos 39 y 55 de la Constitución Política, los cuales permiten el ejercicio pleno del derecho a la asociación sindical y a la negociación colectiva sin restricción alguna, en clara concordancia con lo establecido en los convenios 87 y 98 de la Organización Internacional del Trabajo, convenios que han sido denominados como fundamentales en el marco del derecho público internacional laboral y que regulan de forma integral el ejercicio al derecho de asociación sindical y negociación colectiva sin restricción alguna, lo cual constituye un claro ejemplo de una antinomia constitucional.

Así mismo, el Acto Legislativo 01 de 2005 contradice sustancialmente el denominado bloque de constitucionalidad, integrado a partir de los artículos 
constitucionales $1,4,5,9,25,39,53,55$, y en forma especial los artículo 93 y 94 , que incorporan el derecho de asociación sindical y negociación colectiva previstos en los convenios 87 y 98 de la OIT, los cuales constituyen fuente formal de derecho de rango constitucional en Stricto sensu, criterio sostenido por la doctrina constitucional en forma reiterada.

El Acto Legislativo No. 01 de 2005 no fue objeto de control constitucional toda vez que en las múltiples demandas de inexequibilidad presentadas, la Corte Constitucional se declaró inhibida para estudiar las mismas, al calificarlas como ineptas, muestra de ello la Sentencia C-472 de 2006 con dos salvamentos de voto, lo que hace que la antinomia presentada siga produciendo los efectos jurídicos que hoy se conocen y causan lesión al derecho fundamental de asociación sindical y negociación colectiva.

Se evidencia entonces, ante lo expuesto que corresponde a los jueces de la República en vía ordinaria laboral, frente a los procesos que surjan respecto al tema de pensión convencional resolver la contradicción que surge entre el Acto Legislativo 01 de 2005 que reformó el artículo 48 de la Constitución Política y el Ejercicio del Derecho de Asociación Sindical y Negociación Colectiva establecido en los artículos 39 y 55, concordantes con los convenio 87 y 98 de la OIT, bajo una interpretación sistemática y consecuencialista, que integre el desarrollo del principio de favorabilidad, establecido en el artículo 53 de la Constitución de 1991, así como el Principio pro homine y en consecuencia se reconozca la plena validez de que gozan los acuerdos convencionales, en materia de pensiones de jubilación, previstas en las convenciones colectivas de trabajo, no solo suscritas con anterioridad a la norma en cuestión, sino aquellas que se establezcan aun después de la expedición del Acto Legislativo No. 01 de 2005, como resultado del ejercicio del derecho a la negociación colectiva.

El Congreso de la República al expedir el Acto Legislativo No. 01 de 2005 excedió su competencia legislativa, al efectuar una sustitución de la Constitución en su esencia; cual es un Estado social democrático de derecho bajo el reconocimiento y respecto de la dignidad humana de las cuales hace parte las libertades y garantías sindicales, a partir del derecho fundamental de asociación y su consecuencia jurídica que es la negociación colectiva, generando de paso la antinomia estudiada, toda vez que la reforma por vía de acto legislativo, cual fue la prohibición de la negociación colectiva en materia de pensiones de jubilación, generó una restricción al ejercicio pleno del derecho fundamental de asociación sindical en el marco del artículo 39 de la Constitución Política, inmerso en el Capítulo I título II de la misma, por lo cual conforme al ritual procesal constitucional establecido en el artículo 377 de la C. P. este tipo de reformas deben ser sometidas a referendo, ya que corresponde al constituyente primario según la norma superior referida aprobar las mismas, y no como en el presente caso donde el Congreso de la República en su condición de constituyente derivado se abroga esta competencia en claro desconocimiento del texto constitucional señalado. 
En igual sentido no era dable al constituyente derivado aprobar una enmienda constitucional cuyo contenido fue puesto a consideración del constituyente primario mediante el referendo convocado en la Ley 796 de 2003, artículo 8, no obteniendo la votación necesaria requerida como umbral para su aprobación, lo cual se tradujo como efecto jurídico, en una clara negación a la reforma constitucional planteada por el Gobierno Nacional, por lo tanto no era dable al mismo presentar nuevamente el contenido de este proyecto como acto legislativo ante el Congreso de la República para su aprobación, en su condición de constituyente derivado.

Los convenios denominados esenciales 87 y 98 de la Organización Internacional del Trabajo conservan su pleno vigor jurídico, en razón de que no han sido objeto de denuncia por el Estado colombiano ante la Organización Internacional de Trabajo, conforme al procedimiento establecido para tal fin, ni existe providencia alguna de la Corte de Justicia Internacional que le permita su inaplicación al Estado colombiano, siendo por lo tanto exigible el cumplimiento pleno de estos convenios, en el marco del derecho internacional público que regula los tratados, como lo establece la Convención de Viena (1969), que se funda bajo el principio del Pacta Sut Servanda.

En este orden de ideas se puede concluir que el Acto Legislativo No. 01 de 2005 al prohibir efectuar negociaciones colectivas en materia de pensión de jubilación entre particulares, desconoce de la misma forma el principio liberal del Estado social democrático de derecho, cual es el respecto a la propiedad privada, los derechos adquiridos y el principio de la libertad de empresa, hoy mandatos constitucionales artículos 58 y 333 de la Constitución Política, en concordancia con los tratados internacionales que regulan estas libertades ciudadanas.

Con todo y lo anterior el Acto Legislativo No. 01 de 2005 al establecer una prohibición general respecto a la negociación colectiva en materia de pensiones de jubilación, terminó asimilando el patrimonio y los recursos económicos de capital privado de una persona natural o jurídica con los recursos económicos de carácter público, que resultan asignados a través del Presupuesto General de la Nación, para el pago de pensiones a cargo de este, a pesar de haber sido en esencia el espíritu del acto legislativo referido, tal como se estableció en la exposición de motivos para su aprobación por parte del Congreso, que en esencia era procurar aliviar los pasivos pensionales que están a cargo de la Nación, mostrando una vez más la marcada contradicción existente entre el contenido del Acto Legislativo No. 01 de 2005, la Constitución Política y el contenido de los tratados internacionales debidamente suscritos y ratificados por el Estado colombiano.

Finalmente, se concluye que el Acto Legislativo No. 01 de 2005, que reformó el artículo 48 Constitucional, donde se prohibió en forma general la negociación en materia de pensiones de jubilación vulnera en forma grave los postulados como principios establecidos en el articulado de la Constitución Política que fueron analizados frente al contenido literal del mismo acto legislativo en mención, siendo importante resaltar la sorpresa que causa que una regulación que corresponde al derecho positivo y bajo la dinámica económica y social que resulta cambiante más 
en un modelo de mercados, se haya elevado a rango constitucional en forma pétrea una prohibición que resulta del ejercicio de un derecho fundamental como es el derecho de asociación sindical y la negociación colectiva, lo cual resulta algo exótico en el marco del derecho constitucional desde la perspectiva universal, pues tales disposiciones merecen su desarrollo por transito legislativo en forma normativa, teniendo en cuenta que los aspectos de la Seguridad Social y del Trabajo deben avanzar en forma progresiva como política por parte del Estado, para que de esta forma la condición de vida humana de sus habitantes mantenga un mejoramiento continuo bajo parámetros de equidad, desarrollo y justicia social, que permita de manera funcional el desarrollo armónico de los aspectos en materia de Seguridad Social con relación a las pensiones de jubilación.

\section{REFERENCIAS}

Acevedo, D.Y. (2015). Régimen de transición vs sostenibilidad financiera. Bogotá: Editorial Ibáñez.

Arenas, G. (2007). El derecho colombiano de la seguridad social. Santiago de Cali: Universidad Icesi.

Arrieta, C. (2011). Las reformas al sistema pensional colombiano. Bogotá: FESCOL. Bobbio, N. (1987). Teoría general del derecho. Editorial Debate, Madrid.

Botero, G. (2013). El impacto del Código General del Proceso del Trabajo y de la Seguridad Social. Bogotá: Editorial Ibáñez.

Brontein, A. (2014). Derecho internacional del trabajo. Astrea, Buenos Aires: Universidad de la Sabana.

Cavelier, G. (2002). Tratados de Colombia no perfeccionados. Bogotá: Universidad Externado de Colombia.

Colombia. Asamblea Nacional Constituyente. (1991) Constitución Política de Colombia. Congreso de la República. (22 de julio de 2005) Acto Legislativo 01 del 2005.

Colombia. Consejo Superior de la Judicatura. (s.f.). Práctica Judicial en Derecho Colectivo Laboral. Documento de Trabajo p. 187. Escuela Judicial "Rodrigo Lara Bonilla".

Congreso de la República de Colombia. Proyecto de Acto Legislativo 034 de 2004. Gaceta del Congreso Número 452/2004. Recuperado de http://www.imprenta. gov.co/gacetap/gaceta.mostrar_documento?p_tipo $=36 \&$ p_numero $=034$ $127 \& p \_$consec $=10557$

Declaración Americana de los Derechos y Deberes del Hombre. Recuperado de http://www.cidh.org/basicos/basicos1.htm.

Diario Oficial 45.980 de 25 de julio de 2005. 
Díaz, Y. (2012). La extinción de beneficios pensionales convencionales extralegales y su desaparición a partir de una sustitución de la Constitución Política. Santiago de Cali: Universidad ICESI.

Gascón, M. (1997). La coherencia del ordenamiento. El problema de las antinomias. En AA.VV. Lecciones de teoría del derecho. Madrid: Mc Graw-Hill/ Interamericana de España.

González, G. (2004). Derecho laboral colombiano. Cali: Universidad Icesi.

Guzmán, M.R.B. (2014). El nuevo derecho a la seguridad social del Acto Legislativo 01 de 2005 en Colombia: un caso específico de antinomia y contradicción al interior del bloque de constitucionalidad. Revista. Pensamiento Jurídico, 39.

Guastini, R. (2010). La interpretación de la Constitución. En AA.VV. Interpretación y razonamiento jurídico. Lima: Editorial ARA.

Molina, C.E. (2005). Las normas internacionales del trabajo y su efectividad en el derecho colombiano. Cali: Universidad Icesi.

OIT. (s. f.). Convenio 87. Recuperado de http://www.analitica.com/bitblio/oit/ libertad sindical.asp.

OIT. (s. f.). Convenio 98. Recuperado de http://www.ilo.org/ilolex/spanish/ convdisp1.htm

Oliver, C. (2013). Negociación colectiva y pensiones. Bogotá: Editorial Ibáñez.

Organización Internacional del Trabajo - OIT. (s.f.). Constitución de la Organización Internacional del Trabajo. Artículo 19.1. Recuperado de http://www.ilo.org/ public/spanish/bureau/leg/download/constitution.pdf

Ortiz, J. (2016). Las pensiones consagradas en convenciones colectivas. Bogotá: Editorial Ibáñez.

Pacto Internacional de Derechos Económicos, Sociales y Culturales. Recuperado de http://www.derechos.org/nizkor/ley/pdec.html

Pérez, J. (2004). El derecho constitucional colombiano y el sistema democrático. Bogotá: Temis.

Ribera, T. (2007). Los derechos fundamentales como límites al ejercicio de la soberanía. En Justicia constitucional, derecho supranacional e integración en el derecho latinoamericano. Lima: Universidad Autónoma de Chile. Ceddal, Gijeley.

Rodríguez, S.D., \& Mojica, Y. (2012). Implicaciones que tuvo el Acto Legislativo 01 del 2005 como mecanismo de sustitución constitucional, frente a los derechos adquiridos en materia pensional, en Revista Iter Ad Veritatem No. 10, Ediciones Universidad Santo Tomás, Tunja, Colombia.

Ross, A. (1963). Sobre el derecho y la justicia. Buenos Aires: Editorial Eudeba.

Sáchica, L.C. (1972). Constitucionalismo colombiano. Bogotá: Temis.

Sagues, N. P. (2006). La interpretación judicial de la Constitución (2a. ed.). Buenos Aires: Editorial Lexis Nexis. 